\title{
The Implementation of Inclusive Education and Problems Faced by Teachers in Teaching in Inclusive Education Provider Kindergarten
}

\author{
Joppy Liando ${ }^{1}$
}

\begin{abstract}
:
This study aims to find out the problems faced by teachers in teaching. The study was conducted on July 2012 to December 2012. The research subjects were teachers teaching in inclusive kindergarten. The design of this study was a case study using a qualitative approach. The data were collected using questionnaires, interviews and documentation. Data analysis was conducted during the data collection and after data collection. The research results showed that in general, teachers who taught in inclusive kindergarten did not have knowledge regarding children with special needs, did not have experience dealing with children with special needs, the lack of teamwork, being unable to create good learning in the classroom, the number of students who were too big, the curriculum used was not appropriate with the learning needs of children with special needs, teachers had never had training and workshops on the development of an inclusive classroom, and being unable to develop learning materials related to inclusive environment. As a result, teachers had difficulty in planning the teaching, implementing, and evaluating students' learning outcomes
\end{abstract}

Key Words: Implementation of Inclusive Education, Problems of Teachers in Teaching

JEL Classification: I2, I25

\footnotetext{
${ }^{1}$ Manado State University. College Building in Tondano, joppyliando@yahoo.co.id
} 


\section{Introduction}

There are four foundations that must be used as references in the implementation of inclusive education, namely philosophical foundation, religious foundation, scholarly foundation and juridical basis (Arum, 2005:107). Moreover, Arum states that the juridical basis has hierarchical of constitution, acts, regulations, ministerial policies, director-general policies, local regulations, director policies, up to school rules. The juridical basis also involves international agreements related to education. Based on UNESCO agreement in Salamanca, Spain in 1994, it has been set that worldwide education is inclusively implemented. The agreement provides a right for every child to get education at school, including children who require special education services, either temporarily or permanently, provides a right for every child to go to school located in their community environments inside inclusive classes.

It is believed that inclusive education, in turn, will form one inclusive society (2005:124). World education forum held in Dakar, Senegal, April 2000 resulted in two goals, which were to ensure that by 2015 all children, with special emphasis on girls, children in difficult circumstances and children from minority ethnics, had access to compulsory basic education and free of charge with good quality. By implementing these goals, it means that it increases the number and rate of children at school graduation, eliminates bias at schools, national education systems and curriculum, and eliminates social and cultural discrimination that limits the demand for education of children with diverse backgrounds and abilities (Shaeffer in Ichrom and Watterdal, 2004:5). From the Act of the Republic of Indonesia Number 20 of 2003 on National Education System chapter IV of article 5, subsection 1, it is stated that every citizen has the same right to obtain quality education. Then subsection 2 states that citizens having the physical, emotional, mental, intellectual, and/ or social disorder have a right to obtain special education services (Act of the Republic of Indonesia No.20 of 2003 on National Education System).

There are four factors supporting the implementation of inclusive education, namely philosophical foundation, religious foundation, scholarly foundation and juridical basis. There are also four major challenges that must be faced in relation to the implementation of inclusive education system. The four challenges are actually related to four factors supporting the implementation of inclusive education (Arum, 2005:127).

The implementation of inclusive education in inclusive kindergarten in Manado experienced a challenge. The challenge was the realization of agreement that had been made in Salamanca Spain, known as Salamanca Spain agreement in 1994 and Indonesia had also signed the agreement. In fact, the agreement signed in Salamanca Spain had not been implemented seriously. Schools were given the autonomy to 
develop their creativity in organizing inclusive education, but there was no realization in the implementation, inclusive regular schools were not ready to provide education for children with special needs, and in inclusive regular schools there was no manpower in the field of children with special needs. In general, regular school teachers of inclusive kindergarten had not learned education of children with special needs and they were not trained to develop curriculum in a learning program based on the individual needs of children with special needs, and teachers had difficulties in managing the class because the number of students in a class was too big. It provided impacts on children with special needs who did not receive special services in accordance with their needs. Besides these problems, other problem faced was the lack of manpower in the field of education of children with special needs in inclusive regular kindergarten, and the teachers did not have training to acquire the knowledge and skills of how to deal with children with special needs who had highly heterogeneous ability, problems and needs. These highly heterogeneous abilities, problems, and needs of children with special needs brought impacts on teachers' action in the learning process.

Based on the phenomena that have been stated above, there is a gap between the UNESCO agreement in Salamanca, Spain and the implementation of inclusive education. It has been set in the agreement that the education all over the world is implemented in form of inclusive education, the agreement also states that it is required to give rights to every child to obtain education at school, including children who require special education service through the implementation of inclusive education. Of these problems, the scientific academic thinking is important in the implementation of inclusive education to promote the right of children to education. Inclusive education signals the importance of alternatives to fulfil the right of education for all children. Inclusive education is one solution to the problem of difficulty for children with special needs to get education services as a whole with the problems faced by teachers in the performance of their duties. Based on these explanations, this study aims to find out what the problems faced by teachers in teaching are.

\section{Research Method}

The approach used in this study was a qualitative approach and the design was a case study of the implementation of Inclusive Education and Problems Faced by Teachers in Teaching in Inclusive Education Provider Kindergarten. A qualitative approach in research aims to understand the phenomena of what is experienced by the informants in the study by describing them in form of words and language naturally (Moleong, 2004:6). The research design helps reconstructing and classifying the realities and integrating the data into a set of theoretical constructs if necessary (Goetz and LeCompte, 1981:79). The data were collected using interviews, questionnaires and documentation. The subjects of this study were 7 kindergarten teachers. The data 
obtained from the questionnaires, interviews and documentation were recorded as observations field notes. The data obtained were then analyzed using descriptive analysis. Milles and Huberman (1992) suggest three stages recommended conducting in analyzing the data; they are data reduction, data display, and verification, which are also conducted during and after the collection of research data. By referring to the data analysis recommended by Miles and Huberman, the implementation of research data analysis was conducted by organizing, sorting, grouping, giving meaning and categorizing. The researcher used triangulation and auditing to check the validity of data.

\section{Results}

The results of study were obtained from the analysis of existing data. These results included seven things dealing with problems faced by teachers in carrying out their teaching duties, they were:

1. Teachers did not have the basic knowledge of the education of children with special needs.

The research results showed that teachers who taught in inclusive kindergarten in general did not acquired deep knowledge of children with special needs, the education of children with special needs, and the teaching for children with special needs. This became the cause of difficulties for teachers in providing services for children with special needs in inclusive kindergarten because in inclusive kindergarten there were children with learning difficulties, children with limited cognitive skills, children with high cognitive skills, children with sensory constraints, and children with communication disorders.

\section{Teachers did not have experience in dealing with children with special needs}

The research results showed that there were 11 teachers teaching in inclusive kindergarten did not have experience in dealing with children with special needs that existed at school. Problems faced by teachers in dealing with children with special needs were very complex because teachers did not have the experience on how to deal with children special needs that had very diverse needs.

\section{Problem faced by teachers was in the form of teamwork}

The research results showed that in inclusive kindergarten there were not any special education teachers, as a result, there was no teamwork. Team must work together. In the team there should be special education teachers, regular teachers, psychologist, paediatricians, ENT doctors, speech therapist. Consequently, regular teachers had difficulty in dealing with students in the classroom, because in the classroom there 
were normal children, there were children with high cognitive skills, there were children who had learning difficulties, there were children who experienced sensory constraint, and children with limited cognitive skills.

4. Problem faced by teachers was how to create learning in the classroom

The research results showed that teachers in general had problems in creating effective learning. It was because teachers did not understand the diverse students' capabilities in the classroom and the lack of attention to the characteristics of students with special needs

\section{Number of students in a class was too big}

The research results showed that the teachers had difficulty in managing the class well because the number of students in a class was too big, 15-20 students. As a result, children with special needs did not get better service because teachers gave only limited attention to them.

\section{$\underline{6 .}$ The curriculum used at schools was not suitable for children with special needs}

The research results showed that the curriculum used in inclusive schools was not same for all children. As a result, teachers had difficulty in applying the methods of teaching because the teaching materials were same for all students in a class. It also made students with special needs had difficulty in following the lesson.

\section{Teachers had not attended workshop and training}

Of 7 teachers studied, in general they had never participated in workshops and training on the development of inclusive classroom, improving teachers' knowledge for developing learning materials related to inclusive environment, and teachers had not been trained to develop curriculum in the form of learning programs based on the individual needs of children with special needs. As a result, teachers had difficulty in planning the teaching, implementing it, and evaluating students' learning outcomes.

\section{Discussion}

The research results of the implementation of inclusive education and problems faced by teachers in carrying out their teaching duties included seven things. The first was that teachers did not have basic knowledge of the education of children with special needs. This was a very fundamental problems for teachers because teachers did not have knowledge of who children with special needs were, the classification of children with special needs, their characteristics and problems, rights, liabilities, and needs of children with special needs, the causes and 
prevention, how to perform detection, and how to do the assessment. The knowledge needs to be owned by inclusive regular teachers because teachers without having knowledge of children with special needs will have difficulty in providing services and greatly provide impacts on the children in following the lesson.

The research results showed that teachers had no experience in dealing with children with special needs. If teachers did not have experience in providing education services of special needs, the children with special needs were neglected due to lack of attention. Experiences in dealing with children who have diverse abilities in inclusive schools need to be owned by teachers, because in classrooms there are not only children who have normal ability but also children with special needs. There are several types of children with special needs and each of them has different characteristics. The results of study conducted by Mulyono (1994) show that in regular classes there are exceptional children who should acquire exceptional education services but they do not get it. It is proved by the results of study showing that teachers did not have experience in dealing with children with special needs; as a result, students with special needs did not get services in accordance with the needs and characteristics of each child.

Apparently, in inclusive kindergarten there was no teamwork to deal with children who had varying abilities. In the team there should be special education teachers, regular teachers, psychologists, paediatricians, ENT doctors, and speech therapists. Consequently, regular teachers had difficulty in dealing with students in class. In line with what is stated by Ichrom and Watterdal that in forming an inclusive environment team that is friendly to learning, the team members consist of principal, several teachers, and the school committee (2004: 23-24). He further explains the team approach and collaboration in the process of changes are highly needed. For example, the process of changes in the attitude of everyone participating to be learners and becoming champion. This attitude is creativity, confidence and promotion in terms of the division of tasks and responsibilities (2004: 22). It is very important to note by the principal and teachers in implementing inclusive education in kindergarten. If the team is not working together, it will be fatal for teachers in providing services for children in the classroom.

The problem faced by teachers was how to create learning in the classroom. Arum states that learning can be effective and efficient if teachers understand the diversity of students and implement learning not only based on the characteristics of students in general, but also paying attention to the characteristics of students who have special needs that exist in the class (2005:6). It will be difficult for teachers to create effective learning if they do not understand the characteristics of each student who has different needs 
The research results showed that the number of students in a class was too big, between 15-20 students. It requires the existence of special education teachers to teach big numbers of students in class. Without special education teachers, there are obviously problems faced by teachers, because the ability of children to one another requires different services and even the learning will not be effective, as claimed by Arum that the learning based on students' individual needs will be effective although it is possible that a teacher will be able to teach big numbers of students in one class. Other problem faced by teachers was how to create an effective and efficient learning. The learning will be effective and efficient if teachers understand the diversity and implement the learning by observing the characteristics of students who have special needs (2005:6).

The curriculum used at schools was not suitable for children with special needs. The research results showed that the curriculum used in inclusive schools was same for all children. Thus, it could be said that the learning materials and methods of teaching for all children were same. As a result, smart students would understand the materials more quickly, but students with mental retardation would be delayed or even left behind. This would make teachers have difficulty in serving diverse students if teachers used the same curriculum for all children.

Teachers had not attended the workshop and training. Of 7 teachers studied, in general they had never been to the workshop and training on the development of inclusive classroom, improving teachers' knowledge for developing learning materials related to inclusive education. Ichrom and Watterdal state that workshops and learning opportunities for teachers are needed to introduce and sustain changes (2004:21). Ichrom and Watterdal further explain that it is important to carry out additional workshops to help teachers understanding how students learn, learning new ways, and identifying changes at school that will help students learn (2004:21).

\section{Conclusion}

The problems faced by teachers in carrying out their teaching duties were teachers did not have the basic knowledge of the education of children with special needs, teachers did not have experience dealing with children with special needs, the problem of cooperation in the form of teamwork. The research results showed that in inclusive kindergarten there were no special education teachers. As a result, there was no teamwork. Team must have worked together. The number of students in a class was too big. The curriculum used in the school was not suitable for children with special needs. The research results showed that the curriculum used in inclusive schools was same for all children. As a result, teachers had difficulty in applying methods of teaching. In general, teachers had never been to the workshop and training on the development of inclusive classroom, improving teachers' knowledge for developing learning materials related to inclusive environment, and teachers had 
not been trained to develop curriculum in the form of learning programs based on the individual needs of children with special needs. As a result, teachers had difficulty in planning the teaching, implementing it, and evaluating students learning outcomes.

\section{References}

Abdurrahman M., (1994), "Elementary School Students Needed of Exceptional Education Services, Research Results", Jakarta: Research Institutes of IKIP Jakarta

Arum, W., (2005), "Exceptional Education Perspective and Its Implications for Educational Personnel Preparation", Directorate General of Higher Education of Directorate of Educational Fostering, Educational Personnel, and Higher Education Workforce. Jakarta: Department of National Education

Constitution of the Republic of Indonesia, (2010), "No. 20 of 2003 on National Education System", Jogjakarta: Bening

Goetz, J., LeCompte P. and Margaret, D., (1981), "Ethnographic Research and the Problem of Data Reduction", Anthropology and Education Quarterly, Vol.XII (1).

Ichrom, M., Watterdal, Y.A. and Tertje M., (2004), "Making Inclusive Environment Friendly on Learning", Directorate of Exceptional Education of Director General of Primary and Secondary Education of National Education Department and Braillo Norway, Unicef

Milles, M.B. and Huberman, A.M. (1992), “Qualitative Data Analysis”, Rohidi,T.R. Jakarta. Universitas Indonesia

Moleong, L.J. (2004), “Qualitative Research Method”, Bandung, Remaja Rosdakarya. 